Running head: Public viewpoints on new non-invasive prenatal genetic tests

\title{
POSTPRINT
}

\section{Public viewpoints on new non-invasive prenatal genetic tests PUBLIC UNDERSTANDING OF SCIENCE}

\author{
Hannah R. Farrimond* \\ Susan E. Kelly
}

Citation reference: Farrimond, H. \& Kelly, S.E. (2013) Public viewpoints on new non-invasive prenatal genetic tests, Public Understanding of Science, 22 (6): 736-750.

EGENIS (ESRC Centre for Genomics in Society), Byrne House, University of Exeter, Exeter, EX4 4PJ, UK

Dr Hannah Farrimond is a research fellow at the ESRC Centre for Genomics in Society (EGENIS), University of Exeter. Having completed her PhD in the social psychology of health at UCL, London, she has published work on stigma, masculinities, lifestyle choices and familial responses to genetic diseases/tests. She also writes about novel methodologies and research ethics.

Susan E. Kelly is a senior research fellow at EGENIS. She earned her PhD in Medical Sociology from the University of California, San Francisco, followed by a post-doctoral research position at the Stanford Center for Biomedical Ethics. During this research fellowship, she studied the early development of non-invasive prenatal diagnostic technologies.

*Author for correspondence, $\underline{\text { H.R.Farrimond@ exeter.ac.uk }}$ 
Running head: Public viewpoints on new non-invasive prenatal genetic tests

Key words: PRENATAL, GENETIC DIAGNOSIS, NEW TECHNOLOGY, PUBLIC ATTITUDES, LAY UNDERSTANDINGS, NONINVASIVE, ANTENATAL TESTS

\begin{abstract}
Prenatal screening programmes have been critiqued for their routine implementation according to clinical rationale without public debate. A new approach, non-invasive prenatal diagnosis (NIPD), promises diagnosis of fetal genetic disorders from a sample of maternal blood without the miscarriage risk of current invasive prenatal tests (e.g. amniocentesis). Little research has investigated the attitudes of wider publics to NIPD. This study used Q-methodology, which combines factor analysis with qualitative comments, to identify four distinct 'viewpoints' amongst 71 UK men and women: 1. NIPD as a new tool in the ongoing societal discrimination against the disabled; 2. NIPD as a positive clinical application offering peace of mind in pregnancy; 3 . NIPD as a medical option justified for severe disorders only; and 4. NIPD as a valid expansion of personal choice. Concerns included the 'trivialization of testing' and the implications of commercial/direct-to-consumer tests. Q-methodology has considerable potential to identify viewpoints and frame public debate about new technologies.
\end{abstract}


Running head: Public viewpoints on new non-invasive prenatal genetic tests

'Non-invasive prenatal diagnosis (or NIPD) is the term for a new approach to genetic prenatal diagnosis. NIPD technologies are at various stages of development, but as a collective, aim to offer earlier, easier and less risky genetic testing of the fetus through maternal blood with the potential to replace current diagnostic pathways (e.g. for Down's syndrome diagnosis) and widen prenatal testing possibilities (Hahn \& Chitty, 2008). NIPD technologies have raised considerable debate within bioethical and social scientific communities, but with little attention within public ${ }^{1}$ spheres to date. This paper reports findings from an ESRC funded study of public attitudes towards NIPD. It was conducted in the UK, where prenatal testing is a well-established aspect of obstetric care, and the small amount of media reporting of early NIPD trials has been largely positive.

\section{Non-invasive prenatal diagnosis}

Current screening pathways for common genetic disorders move progressively from noninvasive towards invasive techniques. Non-invasive technologies such as ultrasound are used initially to screen pregnancies. Those identified as 'high risk' are subsequently offered diagnosis through invasive techniques such as amniocentesis or chorionic villus sampling (CVS). These carry a small but significant miscarriage risk (Caughey, Hopkins et al. 2006) and are usually conducted from 15 weeks onwards. One goal of NIPD is to replace this two-step pathway with a one-step early less risky diagnostic test by taking blood from the pregnant woman to analyse the genetic information of the fetus. Non-invasive techniques have been driven by the discovery of 'cell-free fetal DNA' (cffDNA) and RNA (cffRNA) in maternal plasma during pregnancy (Lo, Corbetta et al. 1997). This allows the possibility of obtaining definitive genetic information about the fetus for a limited range of conditions (e.g. sex, paternity, chromosomal abnormalities) from 7 weeks into the pregnancy. DNA-based sexidentification for X-linked disorders, Rhesus D testing and single gene disorder testing are already in limited clinical use. The 'Holy Grail' of NIPD is a replacement diagnostic test for chromosomal abnormalities such as Down's syndrome (Hahn and Chitty 2008). A blood test would also raise the potential of widening diagnostic opportunities rather than restricting them to those at high risk.

\footnotetext{
${ }^{1}$ Although we do refer to 'the public' and 'public attitudes' in this study, we do not believe the public to be a monolithic entity. Rather, we included data from different 'publics' in our sampling.
} 
Running head: Public viewpoints on new non-invasive prenatal genetic tests

A 'simple blood test' for multiple genetic diagnoses also opens up commercial and direct-toconsumer (DTC) opportunities not present in existing invasive test scenarios. Although there are restrictions on sex-determination in clinical settings in the UK, maternal blood tests for sex are available over the internet (e.g. Pink and Blue test offered by Consumer Genetics). This opens the potential for sex selection as well as ‘for information only' use. NIPD paternity testing early in pregnancy is also currently available on the Internet (e.g.

http://www.dnaplus.com/fetal_cell_prenatal_paternity_test.htm). The validity and reliability of such DTC tests are unknown. Companies including Sequenom have also been highly proactive in driving forward commercial Down syndrome blood tests. Issues of the regulation of DTC NIPD tests remain unresolved. The ease of obtaining a blood sample also raises the possibility of pressure or coercion to test.

At present, NIPD applications are limited by current analytic techniques. However, it is likely NIPD will be used for much wider diagnostic practices in the future, known as 'specification creep'(Hall, Bostanci et al. 2009). Possibilities range from testing for most single gene disorders to susceptibility testing for later-onset conditions such as Alzheimers/cancer or for cosmetic 'phenotypic' markers, such as eye colour or muscle (de Jong, Dondorp et al. 2010). Indeed, in 2010, it was announced that it is possible to sequence the whole fetal genome from maternal blood (Lo 2010). In summary, NIPD has the potential to considerably expand the fetal genetic information available early in pregnancy without miscarriage risk and to widen access to diagnostic testing.

\section{Public attitudes towards prenatal testing and NIPD}

In the United Kingdom (UK), public attitudes are shaped by existing prenatal screening programmes and their regulatory context. Pregnant women in the UK have access to fetal anomaly screening through programmes overseen by the UK National Screening Committee (UKNSC). In the UK, all pregnant women are offered an ultrasound scan as a screening tool for fetal anomalies at around 18-20 weeks. In England, an optional maternal serum biochemical screening test for Down's Syndrome is also offered. The UK is one of 25 out of 27 European Union countries in which termination of pregnancy on grounds of fetal abnormality is permitted.

NIPD is thus not an isolated set of new technologies, but part of a historical lineage of prenatal testing which has been the site of extensive discussion within the social sciences. We draw on this literature to consider how the novel features of NIPD raise new and complex social and ethical issues (Newson 2008; Ravitsky 2009; Schmitz, Netzer et al. 2009) and how the public might respond to them. 
Running head: Public viewpoints on new non-invasive prenatal genetic tests

Firstly, NIPD potentially changes key parameters of prenatal diagnosis. Invasive diagnosis creates much anxiety and ambivalence (Markens, Browner et al. 1999). For example, ambivalence about diagnostic testing is a key factor when considering whether to 'choose not to choose' for parents who already have an affected child (Kelly 2009). Taking away the miscarriage risk is a significant change in the risk equation of obtaining prenatal genetic diagnosis. The processes of screening followed by diagnosis through amniocentesis or CVS, which often move decision-making into the second trimester, has led to the social experience of the 'tentative' pregnancy (Katz Rothman 1986). Processes such as bonding or public disclosure are suspended until approval (in the form of the 'correct result' to diagnostic tests) is given to the 'healthy' fetus. NIPD will move the testing period forward, to early in the first trimester. This is likely to lead to pregnancies being experienced as less tentative, with less anxiety whilst waiting for results, and earlier terminations. It may also increase the termination rate overall, if diagnostic testing becomes widespread. Although attitudes to termination are linked with attitudes towards prenatal testing, they are not synonymous (Bryant, Green et al. 2006). However, abortion and religious beliefs represent another dimension on which public attitudes are likely to differ (Bell and Stoneman 2000).

Replacing invasive procedures with a 'simple blood test' could also exacerbate the routinization and normalization of prenatal testing (Press and Browner 1995; Suter 2002). Seror found that $42 \%$ of women who had recently undergone screening for Down Syndrome in France had a 'passive' involvement in the decision; many did not realise that screening was a precursor to decisions about invasive testing and termination (Seror and Ville 2009). It is not clear, however, whether the public themselves have concerns about their independence in making prenatal testing decisions. A Finnish study of medical and lay attitudes towards genetic testing showed that midwives expressed more concern about autonomy of choice than did lay people (Toivianen, Jallinoja et al. 2003).

The potential for earlier, easier and less risky NIPD has also reactivated debates about the eugenic potential of such technologies. As the disability critique has argued, the 'new eugenics' operates through giving individuals (limited) choices around what is an acceptable response to disabled fetuses, and through invoking notions of parental responsibility(Parens and Asch 2000; Kerr and Shakespeare 2002). There are two main objections to abortion on the grounds of disability from this perspective (Parens and Asch 2000). One, the 'expressivist' argument, perceives termination on the grounds of disability as discrimination to both the disabled fetus but also to those who already have the disability. The second, the 'parental attitude argument', sees selective abortion as representing a fundamentally misguided notion of parenthood as an opportunity to pick and choose the perfect child. It is unclear to what extent these perspectives might appear in public responses to NIPD. 
Running head: Public viewpoints on new non-invasive prenatal genetic tests

The notion of 'picking and choosing' one's children is further provoked by the considerable commercial and DTC possibilities opened up by NIPD. It is not clear how different publics would view obtaining commercial or online genetic diagnoses outside traditional medical pathways; as part of the 'commodified pregnancy' process of quality control (Rothman 1988) or as part of an empowerment of parents, giving them the right to choose without health professional involvement (Modra 2006). Commercial NIPD also raises the possibility of increased terminations for non-medical reasons (e.g. for sex selection or paternity) about which the public remain highly ambivalent (Scully, Banks et al. 2006).

To date, most studies of public attitudes towards prenatal testing in general, and NIPD in particular, have involved only women, those in high-risk pregnancies, or parents and families with existing genetic disorders. One study of attitudes towards NIPD amongst pregnant women who had recently undergone invasive diagnosis found that approximately half would still want the confirmation of an invasive diagnosis even if they had a desirable NIPD result (Zamerowski, Lumley et al. 2001). Another study with pregnant women and female medical students showed the majority were positive about seeing NIPD as an asset in prenatal care, but not for sex selection (Kooij, Tymstra et al. 2009).

Little is known about how wider publics might think about the introduction of NIPD. This study set out to investigate public viewpoints of NIPD amongst those often selected in study samples, but also amongst those who are not (men, the child-free, older/younger individuals, those with little experience of genetic disorders or disabilities). There is no doubt that medical and scientific experts are powerful actors in framing the social desirability of a given innovation (Lehoux, Denis et al. 2010). However, it is the wider societal group who set the backdrop for the acceptance or resistance of new and emerging technologies such as NIPD. Furthermore, the implementation of routine prenatal screening programmes on the basis of clinical rationale and technological possibilities without extensive public debate has been extensively critiqued (e.g. Katz Rothman, 1986; Suter, 2002).

Our overall research question was: what are the key viewpoints on emerging NIPD technologies in a UK sample? An additional question was: do participants see NIPD as similar to or different from existing prenatal technologies, and what are their primary areas of concern?

\section{Method}

Given the right method, lay people can produce sophisticated and relevant moral arguments about modern reproductive technologies (Scully, Banks et al. 2006). Q-methodology is a wellestablished, if not well-known method which has been used to study public attitudes towards health behaviours and technologies (e.g. Caughey, Hopkins et al., 2006; Farrimond, Joffe et al., 2010). In a Qsort, participants are asked to sort statements on a topic into a pattern along a dimension of 
Running head: Public viewpoints on new non-invasive prenatal genetic tests

agreement/disagreement (as shown in Figure I). Statements are sorted in relation to each other, so that participants create their 'holistic' viewpoint on the topic (Stenner, Watts et al. 2008). Participants are free to sort in a way that may appear inconsistent or reveals ambiguities (Stainton Rogers 1995). The whole sorts are then correlated and factor-analysed (by-person) to identify groups of sorts which are similar at above chance levels of probability. The end result is a set of statistically independent 'viewpoints' or 'understandings' of a 'limited independent variety' (Keynes 1921). This fits with a social constructionist perspective that individuals within a society are likely to understand a topic using multiple (but not infinite) sets of socially shared discourses (Stainton Rogers 1991). A previous Qmethodology study on Down's syndrome found differences in understandings over the perceived normality of children with the syndrome as well as over the desirability of termination for this condition (Bryant, Green et al. 2006).

We contend that Q-methodology is a method which has much to offer the investigation of how societies and publics perceive new technologies. Methodologically, 'researching the future' is problematic. The term 'NIPD' covers a set of diverse and complex technologies, currently little or unknown to the public. Qualitative methods such as in-depth interviews or focus groups were not suitable given the lack of prior knowledge of the topic. Surveys have been extensively used to tap public attitudes towards technologies such as prenatal testing (e.g.(Singer 1993). Although useful for gaining a broad-brush public opinion, they may provoke a superficial response to limited choice answers. Singer also points out that the scales for prenatal testing are quite unreliable which may be due to unfamiliarity with the topic (in the early 1990s); their lack of stability may also reflect ambivalence on the part of participants. Another set of methodological techniques involve collecting together citizens for deliberation, in citizen's juries and consensus conferences, to discuss controversial topics such as xenotransplantation (Einsiedel 2002) or food technology (Einsiedel, Jelsoe et al. 2001). Q-methodology does not attempt to reconfigure the relationship between policy-makers and the public in a direct sense, but rather 'take the temperature' of attitudes at a given time-point. It also does not focus primarily on consensus, but rather seeks to expose significant differences in viewpoints. Qmethodology was used her to give participants time to explore the issue at hand, in reaction to preexisting statements (so no prior knowledge required) and with the potential to explore ambiguity and contrasting views.

\section{Sampling the 'concourse'}

In Q-methodology, the statements form the sample. These are taken from the concourse, the population of ideas, knowledge, debates, discourses and images on the topic. In this study, the concourse included 
Running head: Public viewpoints on new non-invasive prenatal genetic tests

of medical, academic and media texts on NIPD. As there were few pre-existing public discourses about NIPD, material was sampled and adapted from discussions of prenatal testing, genetic disorders and disabilities in childhood (e.g. web responses to media articles, interview material conducted with parents of children with genetic conditions (Kelly, 2009)). Both authors reviewed the source material and created lists of statements separately, before combining them to generate 157 initial statements. Statements taken from articles/interview were often used verbatim rather than being modified extensively by the authors. The aim was to generate statements using real-life language (e.g. not always removing morally laden terms or controversial positions) to produce authentic responses on the part of participants. These statements were then checked for intelligibility, duplication and balance (Stainton Rogers 1995) and reduced to 70. The Q-sort task was pilot tested. The final set of statements is shown in Appendix I online.

\section{Participants and response rate}

The study had a purposive sampling strategy which sought participants with a variety of relevant experiences. Men and women aged 18-60 were recruited via email, the Internet (e.g., Mumsnet), advertisements in public libraries, community groups (e.g. places of worship) and local newspapers. Participants were given a $£ 15$ voucher upon completion of the task.

Ninety-seven participants who responded to the initial invitation were sent packs. Seventy-three were returned, but two sorts were incomplete and excluded from the study, leaving 71 complete sorts $(73 \%$ response rate).

The characteristics of participants are shown in Table 1.

\section{Procedure}

The research was approved by the Humanities and Social Sciences Ethics Committee, University of Exeter.

The study was carried out by post. After replying to our advertisements, participants were sent a study pack comprising consent forms, the 70 numbered statements on small cards and a study booklet with step-by-step instructions. The study booklet included an introductory paragraph about NIPD to be read before sorting. This briefly described what NIPD was and how it was likely to differ from current prenatal screening (earlier, diagnostic, avoiding the physical risks of amniocentesis, potentially available for a wide range of genetic conditions and commercial use). This paragraph was pilot tested 
Running head: Public viewpoints on new non-invasive prenatal genetic tests

for neutrality and comprehensibility. Participants were then asked for their 'first thoughts' on NIPD in an open comment box before doing the sorting task. Participants were asked to arrange the statements in a fixed distribution according to how much they agreed (+6), disagreed (-6) or were neutral (0) about each statement, with fewer statements at the extremes and more in the middle. Having arranged them in a pattern which reflected their viewpoint, they copied their final card pattern into the paper grid provided. Participants then completed the following sentences (each asked three times): 'I strongly agreed with statement __. The reason was...'; 'I strongly disagreed with statement __. The reason was...' and finally; 'These statements were also interesting to me The reason was...'.

\section{Analysis}

In Q-methodology, the whole sort is correlated with the other whole sorts; a 'by person' factor analysis (unlike traditional correlation in which individual items are correlated with the sample) (Brown 1980). We used PCQ (www.pcqsoft.com). Initially, all 71 Q-sorts were inter-correlated in a large matrix. This matrix was then factor analyzed and rotated using the orthogonal varimax procedure (see Brown, 1980 for the merits of various types of rotation) to produce a set of discrete (not overlapping) factors. Each factor represents a statistically different 'view' on NIPD.

In deciding on the number of factors to retain for rotation, we balanced the amount of variance explained against parsimony (simplicity). We tried a three, four and five factor model. The four factor model was judged best against this criterion, explaining $48 \%$ of the variance. Individual Q-sorts or 'exemplars' loaded significantly onto one of the factors at $0.4(\mathrm{p}<0.01)$. Factor One had 27 exemplars (21\% of the variance), Factor Two had 20 (16\%), Factor Three had $6(7 \%)$ and Factor Four had 3 exemplars (4\% ). Eight 'confounding' sorts which loaded onto more than one factor were excluded, as were seven non-loading sorts. To be able to interpret each factor, the sorts of all the participants who held that viewpoint were merged together using a weighted averages method (see Brown, 1980; Stenner, Watts and Worrell, 2008). This produced four 'arrays' or ideal examples of that particular factor on NIPD (e.g. Factor One's array is shown in Figure I). Table I shows the arrays for all four Factors. Both Table I and Figure I are available in an appendix online.

\section{Interpreting the factors}

Each factor/viewpoint was interpreted by looking at the factor arrays to identify the key statements. These are those ranked at the extremes (i.e. strongly agreed or disagreed with), or those ranked 
Running head: Public viewpoints on new non-invasive prenatal genetic tests

differently compared with the others. ${ }^{2}$ In the interpretation, the key statements for each factor are identified in bold. They are also denoted by a) the number of statement and b) the + or - ranking of the statement in that viewpoint. So $(8:+6)$ means that Statement 8 'These new tests should only be used to find out about serious medical conditions' is strongly agreed with in that viewpoint, ranked as +6 . Statements everyone agreed on (consensus statements) are also identified. To further aid interpretation, comments of participants who held each viewpoint are included in italics.

\section{Findings}

\section{FACTOR ONE: NIPD as discrimination against the disabled}

Factor One represents the viewpoint of twenty-seven participants (19 female, 8 male, average age $=$ 41). Eighteen had children. Thirteen had no experience of severe disability or genetic conditions; three had close relatives/friends with a disability, four had experience through work (e.g., special educational needs, speech therapy), two described themselves as disabled (spina bifida and cerebral palsy), and five had children with disabilities (including Downs syndrome, autism and microcephaly).

Factor One holds NIPD 'to be a form of discrimination against disabled people' $(39:+4 *)$. There is a strong belief that human diversity, including people with disabilities, is normal, valuable and beneficial to society (38: +3*; 41:-6*): 'Society needs diversity and I don't think it makes a difference how many disabled children are in the world' (Participant 4, female, no children). They reject the notion that disability always means suffering and that one ought to fear having a disabled child (11: -4 ; 37: $\left.-4^{*} ; 45:+6^{*}\right)$. Happiness is not just a function of biological ability but is dependent on social acceptance and treatment: 'Many individuals with [genetic] conditions live high-quality productive, happy lives. Even more could do so with greater funding for treatment and support, rather than selective elimination of these individuals before birth' (P14, female, three children).

From this perspective, discrimination is operationalized through the termination of disabled fetuses (42:+4*; 50:-4*). NIPD is thus a 'form of eugenics' (P28, female, four children). Several participants pointed out the continuity between NIPD and older eugenic practices: 'Of course this is discrimination. This testing is to weed out and destroy disabled people-it ISN'T about choice, it's about destruction-

\footnotetext{
${ }^{2}$ We used the criterion of a ranking which is three or more places away from others to denote a significant ranking. These are denoted by a * after the statement.
} 
Running head: Public viewpoints on new non-invasive prenatal genetic tests

as Hitler wanted' (P16, female, three children, one with severe autism). Participants thought NIPD would lead to more terminations of Down syndrome fetuses $(24:+4)$ and greater social pressure to test and terminate in the face of disability $(34:+3 * ; 47:+5 *)$. For some participants, opposition to termination for disability was based on a general anti-abortion stance: 'unless under severe circumstances, I do not believe in abortion, whether it be for social or any other reasons' (P29, male, no children). However, some were ambivalent about rejecting testing outright (12:-1*). Several participants acknowledged it was 'a much better, reduced risk option' (P13, female, no children) and could be used to prepare for the birth of a disabled child. However, any perceived benefits of NIPD were overpowered by fears around 'misuse' of NIPD or 'going too far'.

Participants holding this viewpoint (along with Factor Three) were particularly concerned that NIPD would encourage the trivialization of genetic testing, strongly agreeing 'I worry people will end up testing and having terminations for trivial things' (9:+5): 'it is obvious that women will abort babies in large numbers for the most vague of reasons if given this testing.' (P16). This fear of trivialization was linked to fears that parents are seeking perfection in children $\left(6:+5^{*}\right)$. NIPD would make it 'too easy to start to pick and choose your children' (30:+4*). One participant commented 'It is a sinister fiction of perfection that is operating. This is an impossible but dangerous fantasy' (P48, male, no children). Others saw Statement 30 in terms of representing an undesirable parental expectation: 'I feel very nervous with what seems to be 'provisional love'- parents in effect saying 'I'll only love you if you 're perfect', 'I'll only love you if you're a boy' and so on' (P14, female, three children, third with Down's syndrome).

A final fear was that NIPD would have negative social consequences. This viewpoint was the only one to agree that 'scientists tend to go ahead with these technologies without thinking through the impact on society' $(59:+2 *)$. In particular, concerns centred on the 'type of society' that would result from NIPD, a 'colder and more egoistic' one (P56). The idea of factoring the cost of disabled children due to limited resources (68:-5) was rejected. Participants strongly agreed that 'you can't reduce a human being to their 'worth' in terms of money' $(69:+6) *$. As one participant stated 'I am very concerned government policy and society's values are headed towards valuing wealth above other traits resulting in a lot of consumerism and anxiety in a way that is fundamentally wrong' (P54, female, one child).

\section{Factor TWO: NIPD as a positive clinical application}


Running head: Public viewpoints on new non-invasive prenatal genetic tests

Factor Two represents the position of twenty participants ( 7 men, 13 women, average age 43). Only three had no children. Ten had no experience of severe disability or genetic conditions. One had undergone testing (for BRCA), five had relatives/friends with children with disabilities (e.g. cerebral palsy, Rhetts), two encountered children with disabilities at work (teacher of the deaf, physician) and one had had a daughter with a genetic mutation who had died.

Factor Two represents an essentially positive view of NIPD and prenatal testing which sees the multiple benefits of decreased risk and earlier testing as a way of offering 'peace of mind' during pregnancy, in line with clinical understandings.

From this viewpoint, the world is essentially tolerant of disabled individuals (44:-4): 'I think we live in a diverse society where differences have been debated more openly' (P36, male, no children.)

However, perceiving tolerance towards disability isn't incompatible with screening and selective termination for disability. They strongly reject the idea that NIPD is a form of discrimination (39: -5): 'testing is not discriminatory - thoughtless people are' (P40, female, two children). In this viewpoint, abortion can be understood as a preventive act (42:-5), either preventing the suffering of the disabled foetus itself or the family as a whole: 'having seen the impact a severely disabled child can have on a family, I am in favour of early termination in appropriate cases ' (P2, male, two children).

Factor Two participants largely agree with the clinical rationale for NIPD. Making prenatal testing for genetic disorders easier (for the parents) $\left(16:+5^{*}\right)$ and less risky $\left(17:-5^{*}\right)$ are important pluses about NIPD: 'everyone would prefer to have reduced risks during pregnancy' (P54, female, no children). Clinical applications such as replacing amniocentesis with simple blood tests for Downs $(12:+6)$ and managing high risk pregnancies through Rhesus testing are strongly supported $(36:+4)$. They also support the expansion of testing for serious disorders: 'the more severe genetic disorders they can test for, the better (+6)' although they were neutral about limiting NIPD for serious conditions only $(8:+1)$.

Another key clinical benefit is the potential for earlier testing. Factor Two participants agreed 'the earlier you can have pre-natal tests, the better' $(14:+5)$. They pointed out that NIPD could be used 'For Information Only' rather than termination (52:+4), allowing you to prepare (26:+4). Participant 57 (female, one child and currently pregnant) commented: 'time for planning and information gathering 
Running head: Public viewpoints on new non-invasive prenatal genetic tests can improve peri-natal survival and parents views on their child'. However, the potential for earlier termination is also viewed positively: 'if termination is being considered, the earlier the better' (P2). Overall, earlier testing was seen as a valuable opportunity to gain 'peace of mind' during the pregnancy $\left(22:-4^{*}\right)$, not as something that would increase anxiety (25: -3): 'I can't see how finding out the health of your unborn foetus can cause any more stress than spending 9 months not knowing' (Participant 53, female, two children).

In summary, Factor Two participants believed 'Knowledge is Power' in terms of prenatal decisionmaking. However, they envisaged this within a clinically-led system in which health professionals and counselors offer support as 'these tests would make good genetic counselling all the more important' (29: +4): 'I feel that if more knowledge is made available, it is imperative that this is backed up by professional counseling and support networks (Participant 47, female, one child and currently pregnant)

\section{FACTOR THREE: NIPD for severe disorders only}

Factor Three represents the position of six participants, five women and one man. Their average age was 45. Two had no children. Three had no experience of disability or genetic conditions; the other three had relatives/friends with affected children or conditions (e.g. nephew with severe autism).

Factor Three shares aspects of both Factor One and Factor Two. As in Factor One, there is considerable concern over the social implications of NIPD, particularly the trivialization $(9:+5)$ and routinization of testing $(23:+3)$. There is also a distinctive caution over the consequences of new technologies $(21:+5$, 51: -4): 'Science is often linked with the idea of 'progress' and of being 'correct', therefore individuals who oppose recent developments are frequently attacked as being Luddites or reactionary. However, this distinction often works to obstruct sensible debate (such as this study) on science' (P50, male, no children).

However, unlike in Factor One, there is approval for NIPD but only for the diagnosis of serious medical conditions $\left(8:+6^{*}\right)$. As with Factor Two, therefore, there is agreement on the benefits of diagnosis of severe disorders at birth $(5:+4)$, replacing existing Down's syndrome diagnosis $(18:+4)$ and termination to prevent suffering (42: -5$)$. However, extensions of NIPD use such as having early information about the risk of serious diseases later in life (2: -5) were rejected: 'later life diseases 
Running head: Public viewpoints on new non-invasive prenatal genetic tests

should be left for later life' (P61, female, no children). There is also no justification for making things easier for parents (16: -2), nor is it clear that making things less risky is necessarily without consequences (17: 0). The mantra of 'choice' is rejected, and there is a strong disapproval of the notion of creating 'designer babies': 'This seems to be the start of the slippery slope of choosing your 'designer baby'... I feel very strongly that these tests should only be used to screen for serious medical conditions and not for genetic predispositions to disease or for traits or characteristics' (P62, female, one child).

Factor Three therefore represents a 'high risk' model of diagnostic testing, in which the only ones receiving the opportunity to test would be those at high risk of severe disorders at birth. Correspondingly, there is a very strong emphasis on placing limits on the availability of tests. They agree with Factor Two that genetic counseling is important. $(29:+5)$, but additionally add a strong rejection of commercial testing (53: $\left.+6^{*}, 55:-4\right)$ : 'if these tests are ...restricted to serious medical conditions, there should be no need to go private. I think the internet is the wrong place to go for this information as there may be a need for counseling of the results' (P62).

\section{FACTOR FOUR: NIPD as a personal choice}

Factor Four represents the views of three participants. Two were female, one male. Their average age was 33 years old. They all had children, one having a partner who was seven months pregnant, and one was pregnant. Two had no experience of severe disability/genetic conditions, and one had a cousin with Down's syndrome.

Whereas the notion of 'parental choice' was rejected in Factor Three, here it is a central value. From this 'choice' perspective, the notion of designer babies is not held to be inherently wrong or offensive (unlike in other Factors) $\left(6:-3^{*}\right)$. The notion that it is desirable for people to just accept "what God gave them' is rejected $(63:+5)$. There is a clear prioritization of parental choice about NIPD $(67+5)$ : 'it should be the parents' decision what tests to have and what they want to do with the results' (P22, female, currently pregnant). More specifically, the mother's choice is seen as particularly important (49: +4): 'the mother should have the final say as it's her body and she is more likely to have to cope with any problems than the father' (Participant 22). 
Running head: Public viewpoints on new non-invasive prenatal genetic tests

In this viewpoint, participants dispute the claim that the risks of existing prenatal tests are too high (33:-4*). Furthermore, they agree with expanding testing to include sex determination and testing for non-medical conditions, both rejected in all other factors $\left(4:+6^{*}, 7:-5\right)$ : 'it's their choice to make' (P10, female, two children). There is also support for extending testing to diseases that strike later in life which is not found in other Factors (1: $\left.-5^{*}\right)$. Participant 22 explained her reasoning: 'if family members have suffered these diseases later in life, they may not want a new child to go through the same'.

The desirability of parental choice isn't based on a fear of a lack of tolerance towards disabled individuals: there is a perception that society is more accepting of disabled people than fifty years ago $\left(43:+5^{*}\right)$. However, making choices about whether to have a disabled child is conceptualized as a personal choice for that family, not in terms of social impact: 'parents should have the opt-out- some people will cope better than others' (P37, male, partner pregnant). Perhaps because of the stress on individual decision-making, there is an emphasis on the importance of good genetic counseling (29: $+6)$ on the understanding that having these tests will give you 'peace of mind' $(27:+4)$.

\section{Consensus Statements}

Some statements were so controversial that participants across the factors agreed with each other in strongly supporting or rejecting them. Firstly, all participants disagreed with the idea that 'a damaged baby is a damaged family, however sad that sounds' (46). There was also a strong rejection of the idea of compulsory testing, either for 'societal 'reasons or for those on benefits $(66,70)$ : 'such measurement recalls Nazi procedures and should not be given thought' (P44, male, four children). There was also a consensus that fathers shouldn't be excluded from making decisions about NIPD (48). Finally, all participants rejected the notion that parents should be able to have these tests directly without going through a hospital or doctor (56): 'would be a major problem in terms of interpreting results' (P64, female, three children).

\section{Discussion:}

The findings reveal four major viewpoints in this UK sample about non-invasive prenatal diagnosis as an emerging set of technologies. From these different viewpoints, the potential clinical characteristics of NIPD, such as less risky, earlier and expanded diagnostic testing of the fetus, were viewed in several ways; as a clinical application offering peace of mind (Factor Two), as an opportunity to actualize parental choice (Factor Four), as a medical pathway needing to be restricted to 
Running head: Public viewpoints on new non-invasive prenatal genetic tests

severe genetic disorders (Factor Three) and as a new technology which would lead to the exacerbation of discrimination against the disabled (Factor One). A 'consensus of concern' existed about NIPD being available outside traditional clinical pathways (e.g. commercially/DTC). This discussion considers how we can make sense of these complex and multiple viewpoints from a psycho-social perspective, as well as considering the utility of Q-methodology to investigate public understandings of new technologies.

The benefits of NIPD, in terms of less risky, earlier and easier testing, are seen as distinct advantages in more than one viewpoint. It is interesting to note that despite generalized fears about the societal consequences of NIPD, the idea of replacing amniocentesis with a maternal blood test is not rejected outright even within the first viewpoint (Factor One) and is strongly supported in the others. Factor Two most strongly articulates the benefits of NIPD, broadly in line with the 'safer, easier, earlier' clinical and scientific rationale for developing NIPD (e.g. (Hahn and Chitty 2008). Participants ranked several statements relating to earlier diagnosis very positively, articulating a variety of benefits ranging from 'for information only', to allowing preparation for the birth of a disabled child, to earlier termination. Earlier diagnosis was framed as allowing 'peace of mind'. Katz Rothman's work has shown how current invasive prenatal technologies, such as amniocentesis, have reconstructed the prenatal period as tentative one, full of anxiety and stress, in which reassurance only comes in the form of technologically obtained knowledge. Factor Two articulates the potential advantages of NIPD in terms of this tentative world: NIPD would offer earlier definitive (diagnostic) knowledge, and thus the opportunity for reassurance much earlier in the pregnancy. This is a relatively individualistic rationale for NIPD which fits (as does Factor Four) within a framework in which more genetic information is seen to offer greater 'choice' and 'peace of mind' to autonomous individuals and families (Petersen 2002).

However, this ability to choose is also reconstructed, in other viewpoints, in a negative way, as a fear that the expansion of genetic testing possibilities through NIPD will lead to the "trivialization of testing'. Articulated particularly in Factors One and Three, fears about trivialization are linked to the rejection of 'picking and choosing' and a valuation of natural diversity such as disability. As such, trivialization fears are not fears about having greater information per se, but are rather the fear of the 'trivialization of abortion' (de Jong, Dondorp et al. 2010). In the words of one participant 'women will abort babies in large numbers for the most vague of reasons if given this testing'. The earlier timeframe of NIPD diagnostic testing does open the way for earlier and chemical (as opposed to surgical) termination. Interestingly, although fears about trivialization were strong, few participants supported 
Running head: Public viewpoints on new non-invasive prenatal genetic tests

expanding diagnosis for non-medical reasons such as sex selection or paternity, with only the minority position Factor Four supporting this on the grounds of parental choice.

From the perspective of Factor One, NIPD is not a unique set of technologies. Rather, it must be viewed as part of a longer history of prenatal technologies which have, as identified by Parens and Asch (2000; also Kerr and Shakespeare, 2002), discriminated against the disabled through the practice of selective abortion. NIPD as part of the 'new eugenics' thus finds continuity, at least for a proportion of the public, with the old. The identification of the 'disability critique' viewpoint in this sample is not a trivial one. Kerr and Shakespeare have argued that these voices are often marginalized or drowned out by more dominant clinical and medical discourses in debates about new genetic technologies.

Although the four viewpoints framed NIPD differently, there was also a 'consensus of concern' about the commercial/DTC potential of a diagnostic technology which only requires a small sample of blood (and not the pregnant woman present). The key objection to online or commercial testing was the possibility of prenatal diagnosis outside traditional medical pathways, without the involvement of a health professional. Several reasons were given for this. Firstly, many participants envisaged health professionals as the appropriate group to make decisions about who should access tests and which tests should be available. Health professionals are thus seen as a limiting force against the trivialization of testing. Secondly, many participants saw a need for professional expertise to interpret genetic results and to offer counseling. Placing diagnostic prenatal testing directly in consumers' hands is not seen either desirable or a form of patient empowerment. Participants saw clinicians as a paternalistic 'buffer' against the excesses of commercialism in prenatal testing, rather than as a controlling interest aligned with market forces in the new genetics (Kerr and Cunningham-Burley 2000). This study raises the question of whether there is indeed an appetite for commercial/DTC NIPD amongst different publics, and how they think it should be regulated

This study also supports our contention that Q-methodology is a valuable tool to tap public opinion about complex future technologies. It gave participants an opportunity to critically consider the social, ethical and legal issues around NIPD, simultaneously informing them about the topic and exposing them to a range of values and views, allowing them to form and express their own viewpoint. It exposed differences in views as well as areas of consensus, suggesting directions for public engagement on the topic (e.g. regarding DTC/online regulation).

Q-methodology does have several limitations. One is that it does not tend to involve random sampling, meaning that is not possible to ascertain the prevalence of each viewpoint in the general population. In terms of a response bias, it may be the case that those with strong views or relevant experiences about disability, genetic testing or abortion were particularly motivated to participate. 
Running head: Public viewpoints on new non-invasive prenatal genetic tests

However, looking at the participants' characteristics table (Table II), it can be seen that approximately $50 \%$ of participants had no prior experience of severe disability, genetic conditions or prenatal screening. Our purposive strategy also ensured groups often under-represented in public attitudes to prenatal testing samples, such as men and those without children, also participated.

Q-methodology is not a direct approach to public participation in decision-making processes, as intended with methods such as consensus conferences (although as Einseidel et al. 2001 acknowledges, they often do not have direct impact on policy). Rather it offers an alternative tool for identifying public opinion on complex or controversial technologies, cohered into a set of distinct 'viewpoints.' It has particular utility for identifying minority as well as majority viewpoints (Farrimond, Joffe et al. 2010). In this study, Factor Four is a minority position, one that might easily be lost within a largescale survey. One use of Q-methodology, therefore, would be as the basis upon which to develop a larger-scale public inquiry aiming to incorporate representation from all of the identified 'viewpoints'. As such, it can offer a framework for thinking through and stimulating public debate to feed into policy and clinical spheres ${ }^{3}$.

We do not claim, however, to have exhaustively identified all possible viewpoints from the UK or from different cultures. A different sample (e.g. including potential users of commercial NIPD technologies) or in another culture with different related values and meanings (e.g., towards sex selection or abortion) could be assumed to identify different viewpoints. One productive future line of research would be to conduct comparative Q-methodology studies with other countries. Interesting comparisons could be made with public attitudes in the U.S. where the Food and Drug Administration is already having premarket discussions concerning commercially available non-invasive Down's syndrome tests, or with countries likely to face significant non-invasive sex selection practices in the near future.

In summary, multiple public viewpoints about new prenatal tests are identified in this UK sample, both supporting and questioning the legitimacy of various non-invasive genetic test applications. Fears of the trivialization of testing are likely to be exacerbated by future technological advances, such as whole fetal genome sequencing. Equally, the significant commercial opportunities presented by NIPD are unlikely to lessen; the 'consensus of concern' about DTC/commercialization identified here may increase in parallel. This Q-methodology study represents a strong starting-point for public engagement concerning rapidly advancing NIPD technologies.

\footnotetext{
${ }^{3}$ This Q-methodological study, for example, is being used to initiate discussion about public responses to NIPD at an International Symposium on 'The ethical, legal and social implications of non-invasive prenatal technologies' held at the Brocher Foundation, Geneva in 2011 attended by policy-makers, clinicians and scientists working on NIPD.
} 
Running head: Public viewpoints on new non-invasive prenatal genetic tests

\section{Acknowledgements}

The support of the Economic and Social Research Council (ESRC) is gratefully acknowledged. The work was part of the programme of the ESRC Centre for Genomics in Society.

\section{References}

Bell, M. and Z. Stoneman (2000). "Reactions to prenatal testing: reflection of religiosity and attitudes towards abortion and people with disabilities." American Journal of Mental Retardation 105: 112.

Brown, S. R. (1980). Political subjectivity: Application of a Q methodology in political science. New Haven, Yale University Press.

Bryant, L. D., J. M. Green, et al. (2006). "Understandings of Down's syndrome: A Q methdological investigation." Social Science and Medicine 63: 1188-1200.

Caughey, A. B., L. M. Hopkins, et al. (2006). "Chorionic villus sampling compared with amniocentesis and the difference in the rate of pregnancy loss." Obstetric Gynecology 108: 612-616.

de Jong, A., W. J. Dondorp, et al. (2010). "Non-invasive prenatal testing: Ethical issues explored." European Journal of Human Genetics 18(3): 272-277.

Einsiedel, E. F. (2002). "Assessing a controversial medical technology: Canadian public consultations on xenotransplantation." Public Understanding of Science 11(4): 315-331.

Einsiedel, E. F., E. Jelsoe, et al. (2001). "Publics at the technology table: The consensus conference in Denmark, Canada and Australia." Public Understanding of Science 10: 83-98.

Farrimond, H., H. Joffe, et al. (2010). "A Q-methodological study of smoking identities." Psychology and Health 8: 979-998.

Hahn, S. and L. S. Chitty (2008). "Noninvasive prenatal diagnosis: current practice and future perspectives." Current Opinion in Obstetrics and Gynecology 20: 146-151.

Hall, A., A. Bostanci, et al. (2009). Appendix III: Ethical, legal and social issues arising from cell-free fetal DNA technologies. Cell-free fetal nucleic acids for non-invasive prenatal diagnosis, PHG Foundation.

Katz Rothman, B. (1986). The tentative pregnancy: Prenatal diagnosis and the future of motherhood. New York, Viking Penguin.

Kelly, S. E. (2009). "Choosing not to choose: reproductive responses of parents of children with genetic conditions or impairments." Sociology of Health and Illness 31(1): 81-97.

Kerr, A. and S. Cunningham-Burley (2000). "On ambivalence and risk: Reflexive modernity and the new human genetics." Sociology 34(2): 283-304.

Kerr, A. and T. W. Shakespeare (2002). Genetic politics. Cheltenham, England, New Clarion Press.

Keynes, J. M. (1921). Treatise on Probability.

Kooij, L., T. Tymstra, et al. (2009). "The attitude of women towards current and future possibilities of diagnostic testing in maternal blood using fetal DNA." Prenatal Diagnosis 29: 164-168.

Lehoux, P., J.-L. Denis, et al. (2010). "How medical specialists appraise three controversial health innovations: scientific, clinical and social arguments." Sociology of Health and Illness 32(1): 123-139.

Lo, Y. M. D. (2010). "Maternal plasma DNA sequencing reveals the genome-wide genetic and mutational profile of the fetus." Science Translational Medicine 2(61): 61-91. 
Running head: Public viewpoints on new non-invasive prenatal genetic tests

Lo, Y. M. D., N. Corbetta, et al. (1997). "Presence of fetal DNA in maternal plasma and serum." The Lancet 350: 485-487.

Markens, S., C. H. Browner, et al. (1999). "'Because of the risks': how US pregnancy women account for refusing prenatal screening." Social Science and Medicine 49(3): 359-369.

Modra, L. (2006). "Prenatal genetic testing kits sold at your local pharmacy: Promoting autonomy or promoting confusion?" Bioethics 20(5): 254-263.

Newson, A. J. (2008). "Ethical aspects arising from non-invasive fetal diagnosis." Seminars in Fetal and Neonatal Medicine 13: 103-108.

Parens, E. and A. Asch (2000). The disability rights critique of prenatal genetic testing: Reflections and recommendations. Prenatal testing and disability rights. E. Parens and A. Asch. Washington D.C., Georgetown University Press: 3-43.

Petersen, A. (2002). Facilitating autonomy: The discourse of genetic counselling and the new genetic citizens. The new genetics and the public's health. A. Petersen and R. Bunton. London, Routledge: 135-158.

Press, N. and C. H. Browner (1995). "Why women say yes to prenatal diagnosis." Social Science and Medicine 45(7): 979-989.

Ravitsky, V. (2009). "Non-invasive prenatal diagnosis: an ethical imperative: Correspondence." Nature Review Genetics.

Rothman, B. K. (1988). "Reproductive technology and the commodification of life." Women and Health 13(1-2): 95-100.

Schmitz, D., C. Netzer, et al. (2009). "An offer you can't refuse? Ethical implications of non-invasive prenatal diagnosis." Nature Review Genetics 10.

Scully, J. L., S. Banks, et al. (2006). "Chance, choice and control: Lay debate on prenatal social sex selection." Social Science and Medicine 63: 21-31.

Seror, V. and Y. Ville (2009). "Prenatal screening for Down's syndrome: women's involvement in decision-making and their attitudes to screening." Prenatal Diagnosis 29: 120-128.

Singer, E. (1993). "Public attitudes towards fetal diagnosis and the termination of life." Social Indicators Research 28(2): 117-136.

Stainton Rogers, R. (1995). Q-methodology. Rethinking methods in psychology. J. A. Smith, R. Harre and L. Van Langenhove. London, Sage.

Stainton Rogers, W. (1991). Exploring health and illness: An exploration of diversity. Hemel Hempstead, Harvester Wheatsheaf.

Stenner, P., S. Watts, et al. (2008). Q methodology. The Sage Handbook of Qualitative Research in Psychology. C. Willig and W. Stainton-Rodgers, Sage Publications: 215-239.

Suter, A. M. (2002). "The routinization of prenatal testing." American Journal of Law and Medicine 28(2): 233-270.

Toivianen, H., P. Jallinoja, et al. (2003). "Medical and lay attitudes towards genetic screening and testing in Finland." European Journal of Human Genetics 11: 565-572.

Zamerowski, S. T., M. A. Lumley, et al. (2001). "Favorable attitudes toward testing for chromosomal abnormalities

via analysis of fetal cells in maternal blood." Genetic Medicine 3: 301-309. 
Running head: Public viewpoints on new non-invasive prenatal genetic tests

\begin{tabular}{|c|c|c|c|c|}
\hline $\begin{array}{lc}\text { Statements } & \text { Factors } \\
\end{array}$ & 1 & 2 & 3 & 4 \\
\hline $\begin{array}{l}\text { 1. You shouldn't be able to test a foetus/baby for diseases that strike } \\
\text { in later life (e.g. Alzheimers) }\end{array}$ & 1 & -2 & 2 & -5 \\
\hline $\begin{array}{l}\text { 2. It would be very useful to have early information that your } \\
\text { foetus/baby is at risk of serious diseases in later life (e.g. cancer) }\end{array}$ & -3 & 2 & -5 & 0 \\
\hline $\begin{array}{l}\text { 3.An easy test to select the sex of the foetus/baby will have negative } \\
\text { effects on society }\end{array}$ & 2 & -2 & 2 & -2 \\
\hline $\begin{array}{l}\text { 4. It's up to parents to decide if they want to know the sex of their } \\
\text { baby early on }\end{array}$ & 0 & 1 & 0 & 6 \\
\hline 5. The more severe genetic disorders they can test for, the better & -2 & 6 & 4 & 3 \\
\hline 6. I think it's wrong to want perfect babies & 5 & 2 & 0 & -3 \\
\hline $\begin{array}{l}\text { 7. You should only be allowed to test for the foetus/baby's sex if } \\
\text { there is a risk of a sex-related disease (e.g. Muscular Dystrophy) }\end{array}$ & -1 & -2 & 0 & -5 \\
\hline $\begin{array}{l}\text { 8. These new tests should only be used to find out about serious } \\
\text { medical conditions }\end{array}$ & 0 & 1 & 6 & 0 \\
\hline $\begin{array}{l}\text { 9. I worry people will end up testing and having terminations for } \\
\text { trivial things }\end{array}$ & 5 & 1 & 5 & 1 \\
\hline 10. Sometimes it's easier not to have to make these choices & 2 & 0 & 2 & 3 \\
\hline $\begin{array}{l}\text { 11. If these tests prevent a child's future suffering, even if it means } \\
\text { they are not born, that's a good thing }\end{array}$ & -4 & 2 & 2 & 0 \\
\hline $\begin{array}{l}\text { 12. Replacing amniocentesis with a simple definite blood test for } \\
\text { Down's syndrome would be a big improvement }\end{array}$ & -1 & 6 & 4 & 3 \\
\hline $\begin{array}{l}\text { 13. The harder or more painful a test, the more it makes you think } \\
\text { more about what you are doing }\end{array}$ & 0 & -2 & -3 & -2 \\
\hline 14. The earlier you can have pre-natal tests, the better & -2 & 5 & 3 & -1 \\
\hline $\begin{array}{l}\text { 15. I think it's good NIPD will open up the possibility for screening } \\
\text { for many more conditions in the future }\end{array}$ & -2 & 3 & -2 & 1 \\
\hline 16. Pre-natal testing should be as easy as possible for the parents & -1 & 5 & -2 & 1 \\
\hline $\begin{array}{l}\text { 17. If it removes the risk to the foetus/baby, NIPD can only be a } \\
\text { good thing }\end{array}$ & 0 & 5 & 0 & 1 \\
\hline $\begin{array}{l}\text { 18. Replacing existing tests with a non-risky ones is good, but if it } \\
\text { leads to the expansion of pre-natal testing, I might feel differently }\end{array}$ & 3 & 0 & 4 & -1 \\
\hline $\begin{array}{l}\text { 19. It will become too easy to expand the testing for all kinds of } \\
\text { genetic conditions }\end{array}$ & 2 & -2 & 3 & 0 \\
\hline $\begin{array}{l}\text { 20. A key advantage of NIPD is less stress for the mother during } \\
\text { pre-natal testing }\end{array}$ & -1 & 2 & 1 & 0 \\
\hline $\begin{array}{l}\text { 21. I worry that we don't know what the consequences of } \\
\text { introducing NIPD will be in the future }\end{array}$ & 3 & 0 & 5 & 1 \\
\hline 22. Now everyone who gets pregnant will have to worry about & 1 & -4 & 0 & 1 \\
\hline
\end{tabular}


Running head: Public viewpoints on new non-invasive prenatal genetic tests

\begin{tabular}{|c|c|c|c|c|}
\hline getting genetic test results & & & & \\
\hline $\begin{array}{l}\text { 23. It concerns me that if NIPD just becomes the routine thing for } \\
\text { everyone to do, it will be harder for individuals to opt out }\end{array}$ & 1 & -1 & 3 & -2 \\
\hline $\begin{array}{l}\text { 24. NIPD is bound to result in more terminations of Down } \\
\text { syndrome foetuses }\end{array}$ & 4 & -1 & 4 & 4 \\
\hline $\begin{array}{l}25 . \text { It's bad to get anxious when you are pregnant, NIPD will only } \\
\text { increase anxiety }\end{array}$ & 0 & -3 & -1 & 3 \\
\hline $\begin{array}{l}\text { 26. Knowing about any genetic conditions as early as possible in } \\
\text { pregnancy allows you to prepare }\end{array}$ & 1 & 4 & -1 & 2 \\
\hline $\begin{array}{l}\text { 27. Having NIPD will give you peace of mind, once you know your } \\
\text { baby is ok }\end{array}$ & -1 & 2 & 1 & 4 \\
\hline $\begin{array}{l}\text { 28. I'd worry that the test might be wrong and you might have } \\
\text { terminated a healthy child }\end{array}$ & 2 & 0 & -1 & 1 \\
\hline $\begin{array}{l}\text { 29. These tests would make good genetic counselling all the more } \\
\text { important }\end{array}$ & 0 & 4 & 5 & 6 \\
\hline 30. It would be too easy to start to pick and choose your children & 4 & -1 & 1 & 1 \\
\hline $\begin{array}{l}\text { 31. I worry that a simple blood test could be used to test anyone } \\
\text { without their consent }\end{array}$ & 0 & -1 & -1 & 1 \\
\hline $\begin{array}{l}\text { 32. These tests should be available to every pregnant woman, not } \\
\text { just those at high risk }\end{array}$ & -2 & 3 & -3 & 4 \\
\hline 33. The risks of existing pre-natal tests are too high & 0 & 1 & -1 & -4 \\
\hline $\begin{array}{l}\text { 34. There will be increased social pressure to terminate the } \\
\text { pregnancy if the test is positive }\end{array}$ & 3 & -1 & 0 & -2 \\
\hline $\begin{array}{l}\text { 35. Easier and earlier paternity testing in pregnancy will open up a } \\
\text { whole can of worms }\end{array}$ & 0 & -3 & -2 & -2 \\
\hline $\begin{array}{l}\text { 36. I see a big benefit to NIPD if it helps manage high risk } \\
\text { pregnancies, such as Rhesus (blood type) differences }\end{array}$ & 1 & 4 & 3 & 3 \\
\hline 37. Having a child with a disability is a big fear of mine & -3 & 0 & 2 & 0 \\
\hline $\begin{array}{l}\text { 38. NIPD will lead to fewer disabled children, but less human } \\
\text { diversity }\end{array}$ & 3 & -1 & -1 & -1 \\
\hline 39. NIPD is a form of discrimination against disabled people & 4 & -5 & -2 & -4 \\
\hline $\begin{array}{l}\text { 40. It's selfish to choose to have a disabled child if you know that in } \\
\text { advance }\end{array}$ & -6 & -5 & -2 & -4 \\
\hline $\begin{array}{l}\text { 41. Ultimately, it benefits society if there are fewer disabled } \\
\text { children }\end{array}$ & -6 & -3 & -3 & -3 \\
\hline $\begin{array}{l}\text { 42. There is no such thing as 'therapeutic abortion' as far as the } \\
\text { embryo is concerned }\end{array}$ & 4 & -4 & -5 & -3 \\
\hline $\begin{array}{l}\text { 43. Society is more accepting of disabled people than fifty years } \\
\text { ago }\end{array}$ & 0 & 2 & -1 & 5 \\
\hline 44. Society is increasingly less tolerant of those who are different & -1 & -4 & -2 & -1 \\
\hline $\begin{array}{l}\text { 45. People underestimate the capacity of many disabled children to } \\
\text { be happy }\end{array}$ & 6 & 1 & 1 & 2 \\
\hline 46. A damaged baby is a damaged family, however sad that sounds & -5 & -4 & -4 & -6 \\
\hline $\begin{array}{l}\text { 47. If NIPD goes ahead, it will be harder for parents to choose to } \\
\text { bring a disabled child to full-term }\end{array}$ & 5 & -2 & 1 & 0 \\
\hline $\begin{array}{l}\text { 48. Fathers shouldn't be excluded from making decisions about } \\
\text { things like pre-natal genetic testing }\end{array}$ & 3 & 3 & 3 & 5 \\
\hline $\begin{array}{l}\text { 49. Ultimately, it should be up to the mother whether to go ahead } \\
\text { with NIPD }\end{array}$ & -2 & 1 & 2 & 4 \\
\hline $\begin{array}{l}\text { 50. Women can have abortions for social reasons, why not to avoid } \\
\text { a disabled child? }\end{array}$ & -4 & 0 & 0 & 2 \\
\hline $\begin{array}{l}\text { 51. As soon as the technology becomes available, new tests should } \\
\text { be offered }\end{array}$ & -2 & 1 & -4 & -1 \\
\hline $\begin{array}{l}\text { 52. You don't have to act on the results of NIPD, you can just use } \\
\text { them for information }\end{array}$ & 1 & 4 & 0 & 2 \\
\hline $\begin{array}{l}\text { 53. It's wrong for commercial companies to offer NIPD over the } \\
\text { internet }\end{array}$ & 2 & 3 & 6 & 0 \\
\hline
\end{tabular}


Running head: Public viewpoints on new non-invasive prenatal genetic tests

\begin{tabular}{|c|c|c|c|c|}
\hline $\begin{array}{l}\text { 54. People will want to go private to seek NIPD if the health system } \\
\text { doesn't provide all the tests }\end{array}$ & 1 & 0 & 1 & -1 \\
\hline $\begin{array}{l}\text { 55. If people want to pay to get more information about the genetic } \\
\text { health of their foetus/baby, why not? }\end{array}$ & -3 & -1 & -4 & 0 \\
\hline $\begin{array}{l}\text { 56. Parents should be able to have these tests directly without going } \\
\text { through a hospital or doctor }\end{array}$ & -3 & -5 & -6 & -4 \\
\hline $\begin{array}{l}\text { 57. It should be up to health professionals to decide who has access } \\
\text { to these tests }\end{array}$ & -2 & -3 & 0 & -1 \\
\hline $\begin{array}{l}\text { 58. It doesn't matter whether I approve or not, NIPD will be } \\
\text { common in the future }\end{array}$ & 1 & 0 & 1 & 2 \\
\hline $\begin{array}{l}\text { 59. Scientists tend to go ahead with these technologies without } \\
\text { thinking through the impact on society }\end{array}$ & 2 & -2 & -1 & -1 \\
\hline $\begin{array}{l}\text { 60. People who reject advances in technology to produce healthier } \\
\text { children are living in the past }\end{array}$ & -4 & 0 & -4 & -3 \\
\hline 61. Any opportunity to produce healthier babies should be taken & -3 & 1 & -2 & -1 \\
\hline 62. We are lucky to live in such a scientifically advanced society & -1 & 1 & 0 & 2 \\
\hline $\begin{array}{l}\text { 63. In a way, people in the past had it easier as they just had to } \\
\text { accept what God gave them in terms of children }\end{array}$ & 2 & -1 & -3 & -5 \\
\hline 64. You can't hold back science & -1 & 0 & -1 & 2 \\
\hline $\begin{array}{l}\text { 65. The medical profession has taken over pregnancy and giving } \\
\text { birth }\end{array}$ & -1 & -3 & 1 & -2 \\
\hline $\begin{array}{l}\text { 66. Parents shouldn't be able to opt out of NIPD. Having disabled } \\
\text { children affects society as a whole }\end{array}$ & -4 & -6 & -5 & -6 \\
\hline $\begin{array}{l}\text { 67. It should always be up to the parents to decide whether to have } \\
\text { NIPD or not }\end{array}$ & 1 & 3 & 1 & 5 \\
\hline $\begin{array}{l}\text { 68. In a world of limited resources, you have to factor in the cost of } \\
\text { disabled children }\end{array}$ & -5 & -1 & -3 & -2 \\
\hline $\begin{array}{l}\text { 69. You can't reduce a human being to their 'worth' in terms of } \\
\text { money }\end{array}$ & 6 & 2 & 2 & 0 \\
\hline $\begin{array}{l}\text { 70. Pregnant women who are on benefits should be required to } \\
\text { undergo NIPD }\end{array}$ & -5 & -6 & -6 & -3 \\
\hline
\end{tabular}

Table I: Factor arrays: scores against each item by factor

Strongly disagree........................... Strongly agree

$\begin{array}{rrrrrrrrrrrrr}-6 & -5 & -4 & -3 & -2 & -1 & 0 & 1 & 2 & 3 & 4 & 5 & 6 \\ -10 & 46 & 11 & 2 & 5 & 7 & 4 & 1 & 3 & 18 & 24 & 6 & 45 \\ 41 & 68 & 50 & 37 & 14 & 12 & 8 & 22 & 10 & 21 & 30 & 9 & 69 \\ & 70 & 60 & 55 & 15 & 16 & 13 & 23 & 19 & 34 & 39 & 47 & \\ & & 66 & 56 & 32 & 20 & 17 & 26 & 28 & 38 & 42 & & \\ & & 61 & 49 & 27 & 25 & 36 & 53 & 48 & & \\ & & & 51 & 44 & 29 & 52 & 59 & & & \\ & & & 57 & 62 & 31 & 54 & 63 & & & \\ & & & 64 & 33 & 58 & & & & \\ & & & 65 & 35 & 67 & & & & & \end{array}$

Figure I: Factor array for Factor One 
Running head: Public viewpoints on new non-invasive prenatal genetic tests

\begin{tabular}{|l|l|}
\hline Variable & n=71 \\
\hline Gender & $\begin{array}{l}\text { Male 24 (37\%) } \\
\text { Female 45 (63\%) }\end{array}$ \\
\hline Mean age & $\begin{array}{l}\text { 39.7 years } \\
\text { (s.d. =11.46) }\end{array}$ \\
\hline Socio-economic status & $\begin{array}{l}\text { Higher 46 (65\%) } \\
\text { Lower 21 (29\%) } \\
\text { Unemployed/sick/disabled } \\
4(6 \%)\end{array}$ \\
\hline Ethnicity & $\begin{array}{l}\text { White British 61 (86\%) } \\
\text { White Other 2 (2\%) } \\
\text { Mixed/Asian 4 (6\%) } \\
\text { British 4 (6\%) }\end{array}$ \\
\hline Children & $\begin{array}{l}\text { Yes 52 (73\%) } \\
\text { No 19 (27\%) }\end{array}$ \\
\hline $\begin{array}{l}\text { Experience of prenatal } \\
\text { screening }\end{array}$ & $\begin{array}{l}\text { Yes 41 (58\%) } \\
\text { No 30 (42\%) }\end{array}$ \\
\hline $\begin{array}{l}\text { Experience of } \\
\text { disability/life-limiting } \\
\text { illness }\end{array}$ & $\begin{array}{l}\text { Yes 33 (47\%) } \\
\text { No 38 (53\%) }\end{array}$ \\
\hline $\begin{array}{l}\text { Experience of genetic } \\
\text { conditions or testing }\end{array}$ & $\begin{array}{l}\text { Yes 24 (34\%) } \\
\text { No 47 (66\%) }\end{array}$ \\
\hline
\end{tabular}

Table II: Demographic characteristics of participants 